\title{
Theory and practice of teachers training of preschool bilingual education based on the comprehensive development
}

\author{
Jingjing SHI \\ Xi'an University \\ Xi'an, 710065 , China
}

\begin{abstract}
In recent years, China's pre-school bilingual education has developed rapidly, but there are still such problems as the quality of pre-school bilingual teachers has yet to be improved, pre-school bilingual teachers with good bilingual skills are facing a serious shortage, teaching resources cannot meet market demand. These above problems to some extent hinder the healthy development of China's preschool bilingual education. Given this, the research group proposes a range of strategies which are characterized by highlighting the moral education, aiming at training highquality pre-school bilingual teachers: enriching preschool education resource through creating micro-lectures and excellent teaching materials; realizing sharing learning resources and pre-school education resources; strengthening education teaching practice of students; building a diversified "Happy learning" strategy and developing multiple intelligences evaluation methods.
\end{abstract}

Keywords- preschool bilingual teacher, training strategies, market demand

\section{INTRODUCTION}

In our area where the internationalization of social development is gradual and the society is more and more competitive, to let children to master a foreign language at an early age becomes the first choice for many parents to increase their children's social competition ability. Thus, many kindergartens featuring bilingual education appear in some large and medium-sized cities in our country, with an increasingly strong momentum of development. Experts from society and education pay more attention to young children's bilingual education and related studies emerge in endlessly. Our bilingual education research started relatively late, rising in the 1980s and in the early 1990s, it began to carry out experiments on bilingual teaching in colleges. And the idea that applying this model of bilingual teaching to preschool education was able to receive attention in recent years and gradually applied in practice. From the status quo in terms of pre-school bilingual education, bilingual education, although complies with international development trend of the times and requirements of today's education situation, there is still much to be done for its ancillary elements of education, especially in terms of teaching staff to up to the corresponding standard. That how to train high-quality bilingual teachers has become a focus of current teacher training research and practice. Therefore, it has profound implications on enhancing the quality of the children's bilingual training and improving its nationals to give an analysis of pre-school bilingual teacher demand and the status quo, and then to find out related teacher training constraints, and again to propose workable training programs training program。

\section{REQUIREMENTS AND ANALYSIS OF DOMESTIC PRE- SCHOOL BILINGUAL TEACHERS}

Pre-school teachers with good Bilingual skills are facing a serious shortage in the modern era, although Graduates Employment has become an indisputable fact, pre-school graduates are still highly sought after, especially for bilingual graduates, job prospects are even brighter. With the development of globalization, people's expectations for preschool bilingual education become higher, which laid the foundation of private bilingual education community for kids. Promoted by such factors, private bilingual preschool education is booming, being able to satisfy the demand of the majority of parents for early bilingual education. However, pre-school graduates with good bilingual skills are seriously lacked, which cannot meet the current needs of the education market. According to the survey data, about more than 72 percent of kindergarten require candidates to have good skills both in Chinese and English, so that it can better carry out bilingual teaching.

\section{A. Pre-school bilingual teaching resources cannot meet the market demand}

As China's pre-school bilingual education started late, the teaching resources are lack of appropriate textbooks and supporting bilingual media resources. Today there is no uniform evaluation criteria for preschool teaching resources set by the state, which makes the quality of domestic bilingual textbooks uneven with such problems as the number is small, arbitrariness, the language used is not standardized.

\section{B. The overall quality of pre-school bilingual teachers needs to be improved}

The quality of pre-school bilingual teacher training increasingly aroused the concern and attention from the society and the education sector. As to the problem should be considered in pre-school bilingual teacher training the most, many kindergartens gives the same feedback, $67 \%$ of which think that they should pay attention to ethics training, strengthen the quality of education and comprehensively improve the overall quality of pre-school teachers." 


\section{Training Strategy of Preschool Bilingual Teachers}

Developing scientific and practical pre-professional bilingual training program first, according to Krashen second language acquisition theory and Gardner's theory of multiple intelligences, conducting a training program for preschool bilingual direction, teaching strategies, curriculum materials and evaluation methods. Creating diverse "fun learning" teaching strategies to reinforce students' basic skills-based second language acquisition theory, language input, output, and emotional factors on language, discovering relaxed and happy methods to learn and master a second language and to inspire Pre-school students to be interested in bilingual education, and develop their communication skills, improve the quality of bilingual teaching.

\section{Explore and develop micro-curriculum and quality teaching materials}

Exploring and developing pre-school education network courses of multimedia integrated design, focusing on embodies of bilingual education sustainability. Combing it with "ubiquitous learning theory", integrating the teaching key points and difficult points integration into interesting micro-fine courses to help students understand and master the knowledge, and enhance their learning autonomy.

Realizing open education and pre-school education resources sharing to take advantage of network teaching platform, construct open learning resource library, stimulate students' interest in learning, and guide them to actively carry out independent study.

\section{E. Strengthening Education Teaching Practice}

Personnel training objectives of vocational colleges determined practice teaching link in the teaching course must be strengthened through multi-channel to develop students' vocational skills. Combine teaching practice in the classroom with that outside the school to enrich classroom teaching practices. Integrate the lectures, seminars, counseling, education and other test into teaching practice to make students do learn a little bit, practice a little and then master a little.

Situation 3 Preschool Bilingual Education Teachers Status Quo

Our pre-school bilingual education occurs mainly in kindergartens of economically developed areas. Currently, the Midwest has a great trend. According to statistics, teachers engaged in pre-school bilingual education can be divided into three categories: the first category is the preschool graduates; the second category is graduates majored in English; the third category is hired foreign teachers.

For the above three types of teachers there is a common problem, namely, bilingual teaching methods are simple and lacking of related experience. Among teachers who are engaged in bilingual education in pre-school teaching the number of those who have received training college teachers can reach more than half, while of those who had received pre-school teacher training in bilingual teaching is almost zero. Teachers are lack of knowledge and skills, and experience in bilingual teaching of bilingual education and teaching organization mastery, which will affect the quality of pre-school bilingual teaching.

In the survey, we learned that a bilingual kindergarten teacher is still lack of complete and scientific knowledge of bilingual education, although they generally recognize the importance of pre-school bilingual education, and try some teaching practice, for understanding bilingual pre-school education there are a lot of errors and deviations, which are likely to make the teacher's behavior that violates the laws of teaching in the teaching process.

\section{THEORETICAL RESEARCH AND EXPLORATION IN THE BILINGUAL TEACHER TRAINING}

Local colleges and universities are funded by the local government to cultivate high-culture and skilled talents, which has a wealth of educational resources. The main task is to train application-oriented talents needed by the region's economic development, serving the local economic and cultural development, so the service is their responsibility and rewards to local pre-school teachers and students in local colleges and universities.

Target of training of personnel in the new period reflects national will and the general requirements of social development, which is the main basis for setting objectives of pre-school bilingual education teacher training, while preschool bilingual education teacher training's goal is the reification of talents training goals in new era. As for how to construct knowledge based on knowledge ,taking capacitybuilding as fundamental, aiming to improve the overall quality knowledge of the Trinity, preschool bilingual education teacher capacity and quality of the training objectives we carry out study, so that pre-school bilingual education teacher training reflects the following characteristics :reflecting bilingual teachers outstanding talents, forward-looking, innovative, the character that bilingual education majors are required to be integrated with pre-school education, taking into account the feature that both the overall development of students and the healthy development of personality characteristics .

The course is a pillar of achieving course goals, preschool bilingual education teacher training courses should be made of compulsory courses, elective courses and educational practice course .Combing the three to play the whole function of education. Research on how to select and set before school bilingual education teacher training courses will be carried out. Curriculum basis, the principles of curriculum, classification of course content and others are included. Pre-school bilingual education research faculty building approach, the initial formation of the theoretical system of bilingual teachers in bilingual teacher training are considered as the most direct perpetrators of bilingual education and the most important tasks completed, quality of which plays a key role in reaching its bilingual teaching goals .Therefore, the issue treats study on how to do a good job to strengthen teaching staffs construction , Training Principles establish a teacher-centered professional development, teacher training should focus on helping teachers to solve problems in the process of teaching, by a 
variety of ways and incentives to motivate their inherent passion for learning and motivation, active participation in the training process, a diversified bilingual teacher training methods.

\section{PRACTICE OF TRAINING PRE-SCHOOL BILINGUAL EDUCATION TEACHING STAFF}

Send them out of the garden gate

First, sending teachers to demonstration bilingual kindergarten for in-depth study, observing their bilingual education activities, by which you can strengthen exchanges between the various kindergartens, learn from each other and jointly explore new ways of bilingual education. Second, sending teachers to colleges to learn English, improving their English speaking and writing skills, if conditions is permitted, you can send out teachers in batches for training; if limited, you can make the backbone of teachers who had acquired information carry out promotion among teachers in the Garden in order to complete the full-time teacher training as soon as possible. Third, let high school teachers go out to attend a bilingual teacher training sessions 。 From these training targeted, the kindergarten teachers not only have access to the latest developments in the profession, getting to know the professional education experts, academic leaders, but also can communicate with peers, learn the experience of other park development, which has a very active role on their own professional development.

Kindergartens can cooperate with English teachers in universities, pre-professional teachers and research collaboration teams. First, regularly hire professional teachers in universities to give a lesson to preschool teachers, which not only brings the most cutting-edge developments in the discipline of bilingual education for preschool teachers, but becomes the basic protection of improving English skills of preschool teachers. Second, the majority of kindergartens pay attention to practice, ignore research with no scientific theory guiding teaching behaviors, work in which is of randomness, lacking of scientific theory, causing a lot of bilingual kindergartens to feel that there is limited space for their own development, prospects being slim. So kindergartens can establish with pre-school bilingual education professional research team, while kindergartens can be used as experimental training base for universities to carry out scientific research, sharing research, which will be very useful for both sides. Kindergarten-based training, popularly, is to open a training based on the kindergarten, for curriculum, teachers, child care and the actual environment of the community garden, suitability to carry out the purpose of the training, the training is to improve the operational capacity of the teachers in the garden. With a bilingual teacher training is vigorously promoted, kindergarten-based training becomes more and more popular, because it is economical and flexible, which not only can exercise the ability of teachers in this garden, but also stimulate the competitiveness among colleagues, better for helping carry out bilingual education activities.

\section{CONCLUSIONS}

Of course, the pre-school bilingual teacher training is a continuous process of exploration. In teaching practice, we should really grasp the pre-professional (bilingual direction) training objectives and specifications, and continuously improve and enrich our teachers with high-quality pre-school bilingual education for students. Only students master what they have learned and apply their knowledge can we ensure the personnel training quality, meanwhile, in order training process, we should truly start from students' lifelong development requirements and follow the law of education in order to develop qualified personnel of comprehensive development needed by the society.

\section{ACKNOWLEDGEMENT}

Fund Project: This paper is results of Xi'an Social Fund Project 13WL01.

\section{References}

[1] Xiao Xiangyi. Study before the five-year college Bilingual Education Teachers' Colleges of Teacher Training [D]. Northeast Normal University, 2007.

[2] Research and Exploration Wei Qing preschool bilingual education teacher training [J] intelligence, 2014,27: 77.

[3] Hu Weizhi. Bilingual Teacher Training for child care [J] pure (mid), 2014,22: 156-157.

[4] Wang Fang, Exploration of preschool bilingual teachers training [J] Changchun College of Education, 2013,23: 93-94.

[5] Tan Xuan, Problems and Solutions existing in Preschool Bilingual Education Teachers [J] Suzhou Education Institute, 2014,05: 79-80.

[6] Xue Jing, Study on early childhood bilingual curriculum development and teaching mode [D]. Soochow University,2008.

[7] Huang Fang, On cultivation of New Preschool Bilingual Education Teachers' English ability [J] Sichuan College of Education, 2007,10: 41-43.

[8] Ma Kai, Problems and improvement strategy of preschool bilingual education implementation[J] Modern Primary and Secondary Education, 2013,05: 88-92. 